\title{
Технология очистки и утилизации поверхностных сточных вод и осадков
}

\author{
Ю.Л.Сколубович, НГАСУ (Сибстрин), Новосибирск \\ Е.Л.Войтов, НГАСУ (Сибстрин), Новосибирск \\ А.А.Цыба, НГАСУ (Сибстрин), Новосибирск \\ Д.В.Балчугов, НГАСУ (Сибстрин), Новосибирск \\ Д.Е.Белоногов, НГАСУ (Сибстрин), Новосибирск
}

Одной из основных экологических проблем является сбор транспортировка и очистка поверхностных сточных вод. Большинство существующих систем отвода и очистки поверхностных сточных вод уже не справляются с увеличивающимся объёмом стоков или физически изношены. Основными источниками загрязнения поверхностных сточных вод являются продукты смыва почвенного покрова, разрушения асфальтовых и бетонных поверхностей, истирания автомобильных шин, проливы автотоплива и масел, а также строительные и другие материалы, складируемые на открытых площадках хранения. Поверхностные сточные воды загрязняют водоёмы взвешенными, поверхностно-активными веществами, нефтепродуктами, органическими примесями, ионами тяжёлых металлов и другими загрязнителями. Осадки приводят к загрязнению и заилению русел водотоков, нарушают жизнедеятельность живых организмов, микроорганизмов, оказывают негативное влияние на биоценоз и самоочищающую способность водоёмов.

В статье описывается исследование, целью которого являлась разработка технологии очистки поверхностных сточных вод предприятий угольной промышленности с использованием нового сооружения фильтрования воды - реактора-осветлителя. Экспериментальные исследования проводились в производственных условиях на обогатительной фабрике в Новосибирске. Пилотная установка являлась моделью очистных сооружений ливневых и талых сточных вод предприятия. Изучен состав поверхностных сточных вод предприятия угольной промышленности, разработан проект новой установки очистки сточных вод - реактора-осветлителя. Реагентная очистка ливневой воды проводилась в отстойнике с использованием оксихлорида алюминия в качестве коагулянта. Затем воду осветляли в слое мелкозернистого взвешенной контактной загрузки реактора-осветлителя в скором фильтре, загруженном горелой породой, и на угольном фильтре. Качество очищенной воды соответствовало предъявляемым требованиям. В результате теоретических и экспериментальных исследований была разработана технология очистки ливневых сточных вод промышленных предприятий, которая позволяет сбрасывать их в открытые водоёмы или использовать для утилизации и технического водоснабжения предприятий.

Ключевые слова: поверхностные сточные воды, очистка ливневого стока, взвешенные вещества, нефтепродукты, водоёмы.

\section{Technology for Cleaning and Disposal Surface Waste Water and Sediments}

Yu.L.Skolubovich, NGASU (Sibstrin), Novosibirsk

E.L.Voitov, NGASU (Sibstrin), Novosibirsk

A.A.Tsyba, NGASU (Sibstrin), Novosibirsk

D.V.Balchugov, NGASU (Sibstrin), Novosibirsk

D.E.Belonogov, NGASU (Sibstrin), Novosibirsk

One of the main environmental problems is the collection, transportation and treatment of surface wastewater. Most existing systems for the removal and treatment of surface wastewater can no longer cope with the increasing volume of effluents or are physically worn out. The main sources of pollution of surface wastewater are products of soil washout, destruction of asphalt and concrete surfaces, abrasion of car tires, spills of fuel oil and oils, as well as construction and other materials stored in open storage areas. Surface wastewater pollutes water bodies with suspended, surface-active substances, oil products, organic impurities, heavy metal ions and other pollutants. Precipitation leads to pollution and siltation of the channels of watercourses, disrupts the vital activity of living organisms, microorganisms, and has a negative effect on the biocenosis and self-cleaning ability of water bodies. The aim of the study was to develop a technology for treating surface wastewater of coal industry enterprises using a new filter plant - a clarifier reactor. Experimental studies were carried out in the production conditions of a coal preparation plant in Novosibirsk. The pilot plant was a model of treatment facilities for storm and melt wastewater of the enterprise. The composition of the surface wastewater of a coal industry enterprise was studied, the design of a new facility for wastewater treatment, a clarifier reactor, was applied. Reagent cleaning of storm water was carried out in a sedimentation tank using aluminum oxychloride as a coagulant. Then the water was clarified in a layer of fine-grained suspended contact charge of the clarifier reactor, in a quick filter loaded with burnt rock and cleaned on a charcoal filter. The quality of the treated water was in accordance with the requirements. As a result of theoretical and experimental studies, a technology has been developed for the treatment of storm sewage from industrial enterprises, which allows them to be discharged into open water bodies or used in recycling technical water supply to enterprises.

Keywords: surface wastewater, stormwater treatment, suspended solids, oil products, water bodies. 
В результате интенсивного выпадения атмосферных осадков и снеготаяния происходит сброс дождевых и талых вод с территорий предприятий. В результате в водоёмы поступают поверхностные сточные воды, загрязнённые взвешенными веществами, нефтепродуктами и другими примесями, что оказывает неблагоприятное воздействие на экосистему водоёмов. Характерным и наиболее опасным для водных объектов является загрязнение поверхностных сточных вод нефтепродуктами, как правило, сорбированными на взвешенных веществах.

На промышленных предприятиях существует проблема организации находящихся в неудовлетворительном состоянии систем отведения поверхностных сточных вод. Происходят скопления дождевых и талых вод, что затрудняет движение транспорта, вызывает подтопление зданий, а это приводит к порче оборудования и разрушению строительных конструкций. Также недостаточно быстрое и неполное отведение поверхностных вод ведёт к повышению уровня грунтовых вод, преждевременному ухудшению дорожного покрытия и ухудшению санитарного состояния площадки. При неблагоприятном рельефе местности затопление территорий приводит к катастрофическим последствиям [1-4].

Наряду с проблемами отведения поверхностного стока, существует и проблема его очистки. На большинстве промышленных предприятий очистные сооружения ливневого стока технически несовершенны и не обеспечивают требуемого качества очистки, достаточного для сброса сточных вод в водоёмы или использования в техническом водоснабжении.

Загрязнения, вносимые в водные объекты поверхностными сточными водами, оказывают существенное влияние на санитарное состояние водоёмов. Наиболее неблагоприятное влияние оказывают взвешенные вещества и нефтепродукты. При высоких концентрациях взвешенных веществ, происходит их частичное осаждение в створе выпуска поверхностных сточных вод и ниже по течению. Это приводит к заиливанию водоёмов и препятствует нормальному протеканию биологических процессов на дне водоёма. Органическая часть растворённых взвешенных веществ постепенно окисляется растворённым в воде кислородом. Поступающие от автомобильных дорог, плавающие нефтепродукты способствуют образованию на поверхности водных объектов нефтяной плёнки и снижению количества растворённого кислорода, что губительно сказывается на жизнедеятельности водных организмов.

Оседающие в водоёмах тяжёлые остатки нефтепродуктов, разлагаясь, загрязняют воду продуктами распада, часть из них выносится на поверхность в виде пузырьков газа, образуя нефтяное пятно ${ }^{1,2}[5]$.

Особую опасность представляет длительное воздействие небольших концентраций нефтепродуктов, так как углево- дороды, входящие в их состав, способны растворять другие загрязняющие вещества.

Талые воды имеют в своём составе растворённые химические вещества противогололёдных материалов (в качестве которых применяются реагенты, содержащие хлористый натрий, железистый цианид, соли кальция и магния и др.), природа воздействия которых на окружающую среду до сих пор детально не изучена [6; 7].

В результате, можно сделать вывод, что обеспечение организованного отвода и требуемой очистки поверхностных сточных вод является важной задачей. Даже в сточной воде, прошедшей все этапы очистки, включая биологическую, остаётся до 10\% растворённых органических и минеральных загрязняющих веществ. Пригодной для потребления в качестве питьевой вода становиться после многократного разбавления чистой природной водой. Попадание загрязнённых поверхностных сточных вод в водную среду приводит к снижению её продуктивности как среды обитания, делая невозможным использование такой воды человеком для бытовых, сельскохозяйственных и промышленных процессов.

В зависимости от предъявляемых требований используют методы очистки поверхностных сточных вод, основанные на физических, химических и физико-химических процессах, протекающих в очистных сооружениях, или естественных биологических процессах самоочищения, происходящих в почве или водоёмах.

Процесс выпадения атмосферных осадков носит вероятностный характер. При этом дождевой сток характеризуется чрезвычайной нестационарностью, как по расходам, так и загрязняющим компонентам, концентрация которых в течение одного дождя изменяется в самых широких пределах. Поэтому важнейшим вопросом технологии очистки поверхностных сточных вод является усреднение расхода и состава стоков перед подачей на очистку. В связи с этим в качестве обязательного элемента в состав очистных сооружений поверхностных сточных вод включаются сооружения для регулирования расхода и усреднения состава стоков.

В связи с этим исследования, направленные на изучение качества поверхностных сточных вод, разработку сооружений регулирования стоков по расходу и концентрации, а также их эффективной очистки, являются актуальными и своевременными.

Целью исследования являлась разработка технологии очистки поверхностных сточных вод предприятий угольной промышленности с применением нового фильтровального сооружения - реактора-осветлителя.

Для реализации поставленной цели был проведён анализ качественного состава поверхностных сточных вод и экспериментальные исследования по очистке поверхностного стока; были разработаны сооружения и технологии очистки поверхностных сточных вод.

${ }^{1}$ Рекомендации по расчёту систем сбора, отведения и очистки поверхностного стока с селитебных территорий, площадок предприятий и определению условий выпуска его в водные объекты. - М. : ОАО «НИИ ВОДГО», 2014. - 88 с.

${ }^{2}$ Временные рекомендации по предотвращению загрязнения, отведению и очистке поверхностного стока с территории предприятий угольной промышленности. - Пермь : ВНИИОСуголь, 1985. - 78 с. 
Экспериментальные исследования проводились в производственных условиях углеобогатительной фабрики Новосибирска. Экспериментальная установка представляла собой модель очистных сооружений ливневых и талых сточных вод предприятия. Использовались натуральная поверхностная сточная вода, поступающая в период дождя из внутриплощадочной ливневой канализации (рис. 1, 2).

Работа установки осуществлялась следующим образом: ливневая вода из колодца ливневой сети насосом по трубопроводу

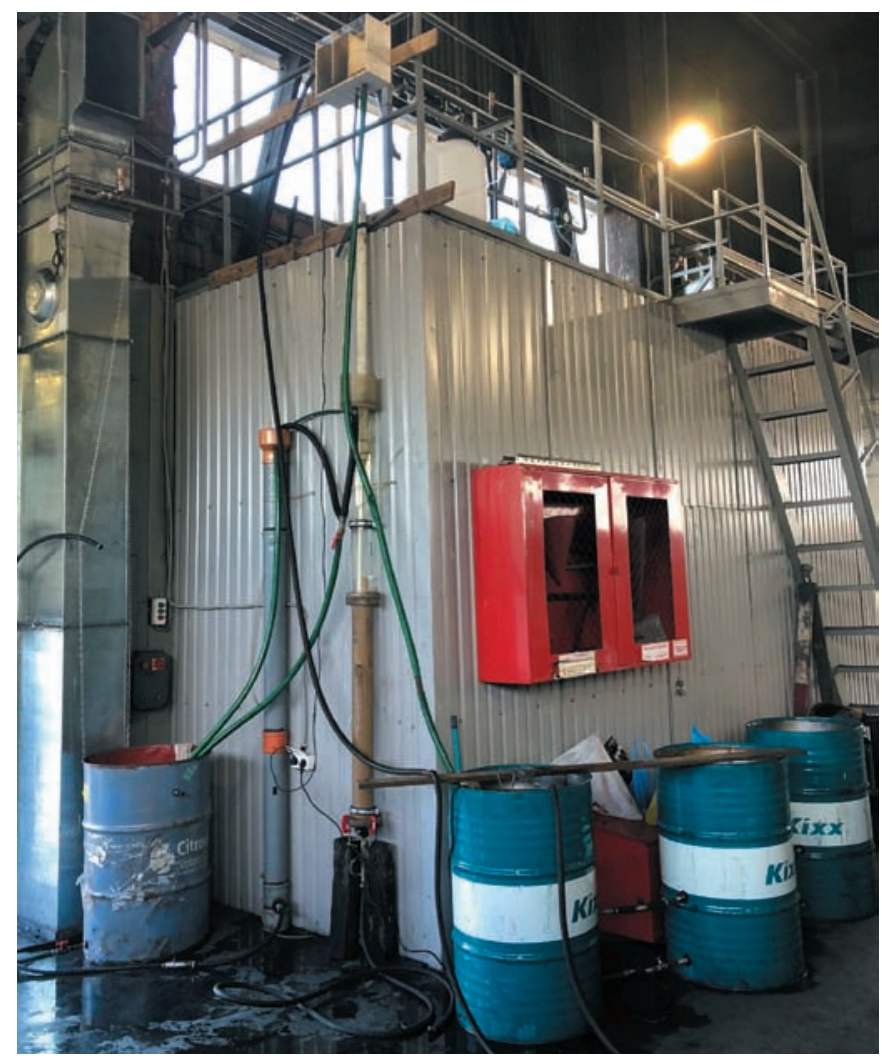

Рис. 1. Экспериментальная установка. Внешний вид

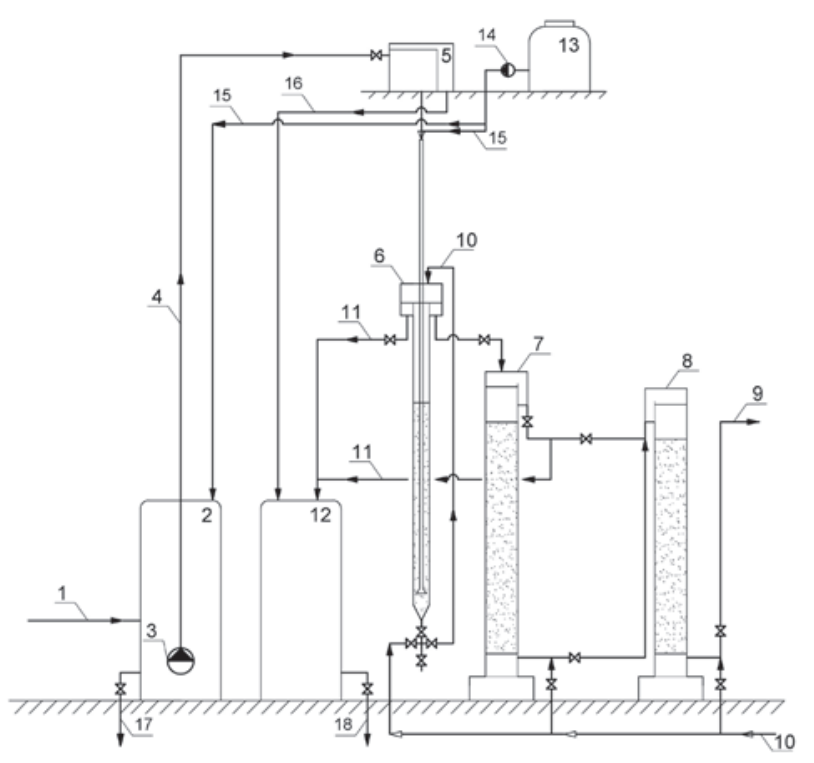

Pис. 2. Схема экспериментальной установки
(1) подавалась в накопительный бак, моделирующий отстойникнакопитель ливневой воды (2). Температура воды составляла 10-12 ${ }^{\circ}$ С. Одновременно с подачей сточной воды в отстойники вводился раствор оксихлорида алюминия с оптимальной дозой 10 мг/л. Оптимальная доза была предварительно определена путём пробного коагулирования по стандартной методике [2].

Отстаивание воды происходило в непроточных условиях в течение 60-90 минут. После отстаивания гидроксидный осадок сбрасывался по трубе (17) и исследовался на влажность и содержание примесей. Объём осадка составлял до $10 \%$ от объёма обрабатываемой воды. Осветлённая вода из отстойника с помощью подкачивающего насоса (3) по трубопроводу (4) подавалась в бак постоянного уровня (5), а затем дозированным расходом - в реактор-осветлитель (P0) (6), наполненный кварцевым песком. Крупность песка составляла 0,4-0,8 мм, высота загрузки 1 м.

Далее осветлённая вода самотёком поступала в безнапорный скорый фильтр (7) с загрузкой из дроблёной горелой породы крупностью зёрен 1-2 мм. Затем вода поступала в угольный фильтр (8) с загрузкой из активированного угля марки АГ-3 с крупностью зёрен 1-2,5 мм. Очищенная вода сбрасывалась по трубе (9) в хозяйственно-бытовую канализацию. По истечении времени защитного действия взвешенной контактной загрузки РО и ухудшении качества осветляемой воды ниже установленного санитарного предела - 3 мг/л

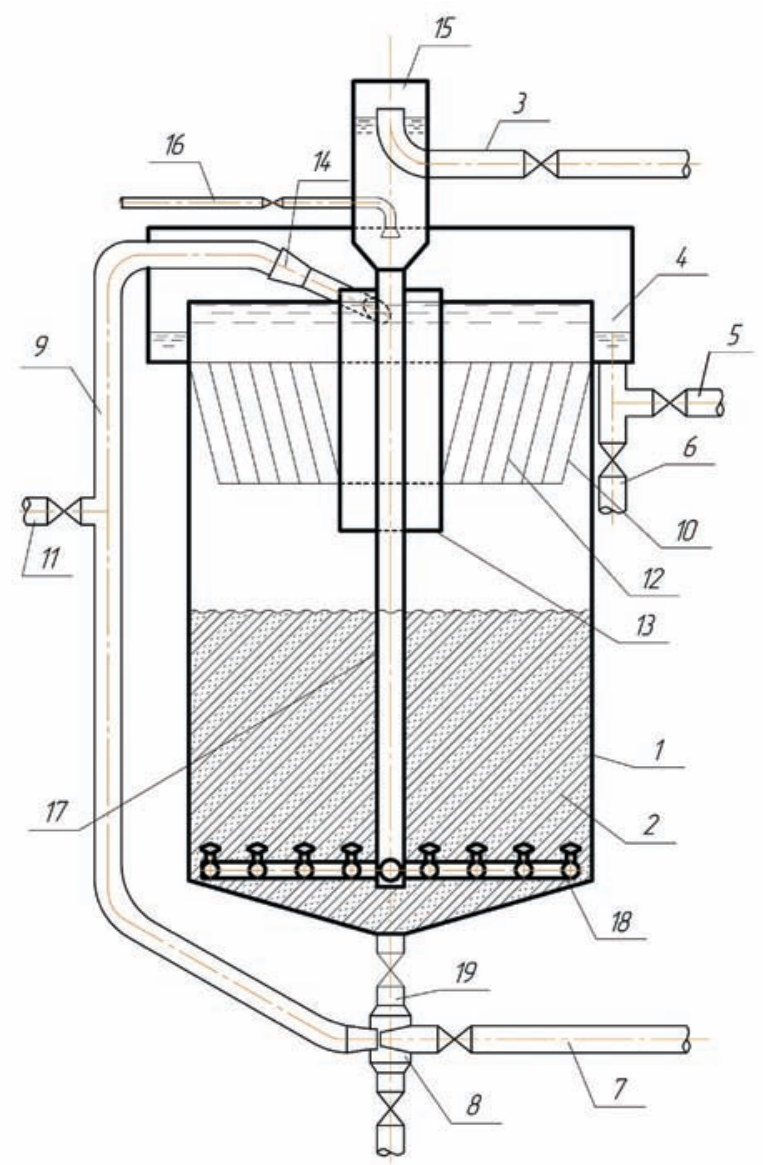

Рис. 3. Схема реактора-осветлителя 
по содержанию взвешенных веществ, производилась эжекторная промывка загрузки реактора-осветлителя и обычная водяная промывка скорого и угольного фильтров.

Принципиально новым сооружением предварительной очистки сточной воды фильтрованием по принципу работы и конструкции является реактор-осветлитель ${ }^{3}$. Принцип работы Р0 (рис. 3) основан на восходящем фильтровании воды через слой увеличенной по высоте на $10 \%$ мелкозернистой загрузки.

Реактор-осветлитель работает следующим образом. По трубопроводу подачи воды на осветление (3) исходная вода, обработанная коагулянтом, подаётся в воздухоотделитель (15). По трубопроводу (16) при необходимости в зависимости от качества осветляемой воды вводится раствор флокулянта. По вертикальной опускной трубе (17) вода поступает в нижнюю часть корпуса (1), равномерно распределяется по площади зоны осветления устройства распределительной колпачковой системой (18) и фильтруется снизу вверх через слой загрузки (2) со скоростью, обеспечивающей её взвешивание. В качестве контактной загрузки (2) используется кварцевый песок или любой другой мелкозернистый материал, удовлетворяющий требованиям по механической прочности и химической стойкости. Во взвешенном слое расширенной загрузки происходит задержание и накопление осадка. Часть хлопьев осадка выносится из слоя, но задерживается тонкослойным модулем (12), сползает по наклонным стенкам его колец вниз и оседает на поверхность контактной загрузки. В результате достигается высокий эффект осветления воды, повышается производительность устройства.

Осветлённая вода собирается жёлобом (4) и выводится трубопроводом (5) из реактора. По истечении времени защитного действия расширенной контактной загрузки и ухудшении качества осветляемой воды производится эжекционная промывка контактной загрузки с помощью водяного эжектора (8) и водовоздушного эжектора (14). Подача исходной воды на период промывки (10-15 мин.) не прекращается, а вся вода сбрасывается на обработку для повторного использования, что способствует процессу промывки и сокращает её продолжительность. Водопесчаная пульпа эффективно отмывается при её тангенциальном движении в сепараторе (13). Промытые зерна контактной загрузки осаждаются во взвешенный слой, а осадок отводится с отработанной промывной водой через сборный жёлоб (4) и трубопровод (6). Вынос контактной загрузки в сборный жёлоб предотвращается тонкослойным модулем (12). При необходимости замены контактной взвешиваемой загрузки или опорожнении устройства для очистки воды пульпа выпускается из него по трубопроводу (11).

За счёт устранения застойных зон в местах контакта зёрен, большой удельной поверхности зёрен мелкозернистой загрузки из горелых пород увеличивается производительность РО и грязеёмкость его фильтрующей загрузки. Рабочие скорости фильтрования на РО превышают рекомендуемые СНиП 2.04.02-844 скорости фильтрования воды на скорых фильтрах до полутора раз. При этом за счёт восходящего фильтрования воды происходит процесс контактной коагуляции в загрузке Р0, благодаря которому происходит снижение доз реагентов до 50\%, по сравнению со скорыми фильтрами. В реакторе-осветлителе предусматривается эжекционная промывка загрязнённой загрузки исходной водой, которая позволяет добиться эффективной промывки всего её объёма без образования агломератов примесей воды и зёрен нижних поддерживающих слоёв, свойственного контактным осветлителям. Эжекционная промывка позволяет сократить расход чистой воды на промывку более чем в два раза по сравнению с промывкой скорых фильтров и контактных осветлителей. Таким образом, РО сочетает в себе достоинства зернистых фильтров и осветлителей с взвешенным осадком, обладает высокой производительностью, надёжностью работы и низкой эксплуатационной стоимостью [8].

Для определения качественного состава поверхностных сточных вод предприятия отбирались пробы неочищенных ливневых вод из конечной точки внутриплощадочной дождевой сети углеобогатительной фабрики Новосибирска. Осреднённые значения показателей за осенний период исследований представлены в таблице 1

Во время проведения испытаний для определения эффективности работы технологической схемы очистки (см. рис. 1), осуществлялись отборы проб в следующих точках: колодец ливневой сети, после отстойника, после реактораосветлителя, после скорого и угольного фильтров. Анализ эффективности работы технологической схемы оценивался по содержанию нефтепродуктов, взвешенных веществ, железа и фенолов. Результаты экспериментальных исследований, сведены в таблицу 2.

Таблица 1. Анализ качества поверхностных сточных вод

\begin{tabular}{|c|c|c|c|c|}
\hline $\begin{array}{l}\text { № } \\
\text { ח/ח }\end{array}$ & Показатели & $\begin{array}{c}\text { Единицы } \\
\text { измерения }\end{array}$ & ПдК & Результат \\
\hline 1. & Нефтепродукты & мг/дм ${ }^{3}$ & 0,05 & 0,382 \\
\hline 2. & Взвешенные вещества & $\mathrm{Mr} / \mathrm{AM}^{3}$ & 10,00 & 110,67 \\
\hline 3. & Водородный показатель & $\mathrm{pH}$ & $6,0-9,0$ & $7,5-8,0$ \\
\hline 4. & Аммоний-ион & $\mathrm{Mr} / \mathrm{AM}^{3}$ & 0,50 & 1,25 \\
\hline 5. & Азот общий & $\mathrm{Mr} / \mathrm{MM}^{3}$ & 0,40 & 1,5 \\
\hline 7. & Фенол & $\mathrm{Mr} / \mathrm{Am}^{3}$ & 0,001 & 0,006 \\
\hline 8. & Железо & $\mathrm{Mr} / \mathrm{Am}^{3}$ & 0,10 & 0,51 \\
\hline 9. & Алюминий & $\mathrm{Mr} / \mathrm{gm}^{3}$ & 0,04 & 0,89 \\
\hline 10. & Медь & мг/дм ${ }^{3}$ & 0,001 & 0,002 \\
\hline 12. & Цинк & мг/дм ${ }^{3}$ & 0,01 & 0,014 \\
\hline 13. & Никель & $\mathrm{Mr} / \mathrm{AM}^{3}$ & 0,01 & $<0,001$ \\
\hline 14. & Хром & $\mathrm{Mr} / \mathrm{Am}^{3}$ & 0,07 & $<0,001$ \\
\hline 15. & Кадмий & $\mathrm{Mr} / \mathrm{AM}^{3}$ & 0,005 & $<0,0001$ \\
\hline
\end{tabular}

3 Пат. 181324, Российская Федерация, МПК С02F 3/10, C02F 3/26, CO2F 1/52 «Устройство для очистки воды» / Е.Л. Войтов, Ю.Л. Сколубович, А.Ю. Сколубович; Заявитель и патентообладатель НГАСУ. № 2017144382; Опубл. 10.07.2017; Бюл. № 19.

${ }^{4}$ СНиП 2.04.02-84. Водоснабжение. Наружные сети и сооружения / Госстрой СССР. - М : Стройиздат, 1986. - 136 с. 
Качество очищенной воды отвечало ПДК (табл.1).

На основании проведённых исследований разработана технология очистки поверхностных вод (рис. 4). В состав технологической схемы входят, отстойники-регуляторы с встроенными решетками и песколовками. Перед отстойниками в исходную воду вводится коагулянт. После непроточного отстаивания в течение одного часа отстоянная сточная вода подаётся насосами на реакторы-осветлители через смесители-воздухоотделители. В трубопровод перед смесителями вводится раствор флокулянта. В контактной расширенной загрузке РО происходит задерживание хлопьев гидроксида алюминия и сорбированных на них примесей воды. Затем вода поступает в скорые фильтры, при необходимости подвергается сорбционной очистке на фильтрах, загруженных гранулированным активированным углем, и обеззараживается УФ-облучением.

Качество очищенной ливневой воды позволяет сбрасывать её в открытые водоёмы либо использовать на нужды оборотного технического водоснабжения.

Промывка реактора-осветлителя и фильтров производится ежесуточно очищенной промывной водой, подаваемой промывным насосом из одной секции отстойника промывной воды, и сбросом в другую его секцию. После реагентной

Таблица 2. Анализ очищаемых поверхностных сточных вод

\begin{tabular}{|l|c|c|c|c|c|}
\hline \multicolumn{1}{|c|}{ Показатели } & $\begin{array}{c}\text { Исходная } \\
\text { вода }\end{array}$ & $\begin{array}{c}\text { После } \\
\text { отстойника }\end{array}$ & $\begin{array}{c}\text { После } \\
\text { реактора- } \\
\text { осветлителя }\end{array}$ & $\begin{array}{c}\text { После } \\
\text { скорого } \\
\text { фильтра }\end{array}$ & $\begin{array}{c}\text { После } \\
\text { угольного } \\
\text { фильтра }\end{array}$ \\
\hline $\begin{array}{l}\text { Нефтепродукты, } \\
\text { мг/дм }\end{array}$ & 0,382 & 0,362 & 0,137 & 0,062 & 0,01 \\
\hline $\begin{array}{l}\text { Взвешенные } \\
\text { вещества, мг/дм }\end{array}$ & 110,67 & 45,75 & 2,9 & 2,5 & 1,5 \\
\hline Железо, мг/дм ${ }^{3}$ & 0,51 & 0,098 & 0,05 & 0,05 & 0,05 \\
\hline Фенол, мг/дм 3 & 0,0126 & 0,0126 & 0,0123 & 0,0123 & 0,001 \\
\hline
\end{tabular}

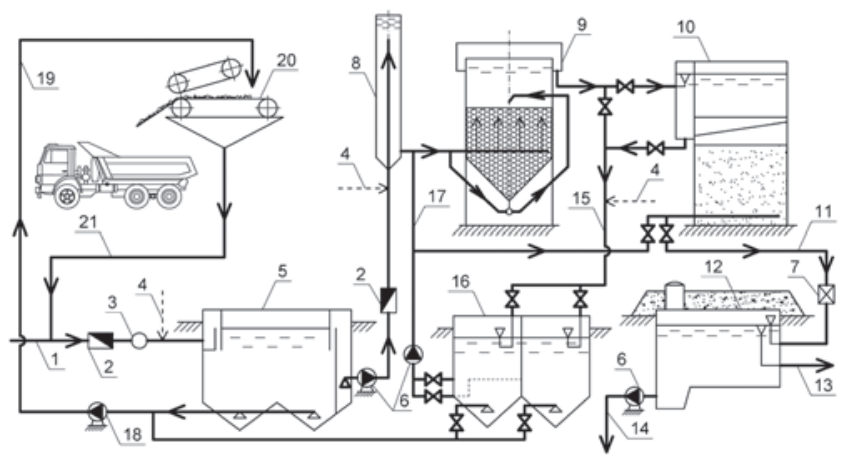

Рис. 4. Технологическая схема очистки поверхностных вод: 1 - подача исходной воды; 2 - расходомер; 3 - мутномер; 4 - ввод химических реагентов; 5 - отстойник-регулятор; 6-насосы; 7-озонатор; 8-смеситель-воздухоотделитель; 9 - устройство для очистки воды (фильтр); 10 - безнапорный скорый фильтр; 11 - очищенная вода; 12 - резервуар чистой воды; 13 - сброс в водоём; 14 - подача воды на производственные нужды; 15 - отвод промывной воды; 16 - непроточный отстойник; 17 - подача промывной воды; 18 - шламовый насос; 19 - на обезвоживание; 20 - фильтрпресс; 21 - подача воды на повторную очистку очистки промывная вода используется повторно. Пополнение запаса промывной воды осуществляется сбросом первого фильтрата с фильтров.

Образующиеся осадки ливневой и промывной воды обезвоживаются и вывозятся на утилизацию для производства строительных изделий [9].

***

Результаты проведённого исследования состоят в следующем.

1. Разработана технология очистки поверхностных сточных вод предприятий угольной промышленности с применением нового фильтровального сооружения - реактораосветлителя.

2. Результаты экспериментальных исследований доказали возможность очистки поверхностных сточных вод с промышленных территорий по предлагаемой технологии до качества, позволяющего сбрасывать их в открытые водоёмы или повторного использовать в техническом водоснабжении предприятии.

3. Водопроводный осадок утилизируется в производстве строительных изделий.

При этом, наряду с решением экологического вопроса охраны окружающей среды, осуществляется направленное регулирование свойств бетонных смесей и получение строительных изделий с заданными свойствами.

\section{Литература}

1. Алексеев, М.И. Организация отведения поверхностного (дождевого и талого) стока с урбанизированных территорий : учеб.пособие / М.И. Алексеев, А.М. Курганов. - М. : АСВ, 2000. - 352 c.

2. Молоков, М.В. Дождевая канализация площадок промышленных предприятий : производственно-практическое издание. - М.-Л. : Стройиздат, 1964. - 184 с.

3. Волчек, А.А. Ливневой сток как источник загрязнения поверхностных вод / А.А. Волчек, И.В. Бульская // Вестник Брестского государственного технического университета. 2012. - Вып. 2. - С. 41-43.

4. Очистка ливневого поверхностного стока на осветлительно-сорбционных фильтрах с применением катионных флокулянтов / Ж.М. Говорова, О.Б. Говоров, Л.В. Гандурина, Л.Н. Буцева // Очистка сточных вод : Сборник трудов НИИ ВОДГЕО. - М. : ОАО «НИИ ВОДГО», 2004. - Вып. 7. - С. 52-61.

5. Игнатьева, Л.П. Санитарная охрана водных объектов : учебное пособие / Л. П. Игнатьева, М. О. Потапова. - Иркутск : ИГМУ, 2016. - 97 с.

6. Response by white birch (Betula papyrifera) to road salt applications at Cascade Lakes / A. M. Fleck, M. J. Lacki, J. Sutherland // Journal of Environmental Management. 1988. - Vol. 12. - № 1. - P. 369-377.

7. The effects of road deicing salt on the levels of ions in roadside soils in southern Ontario / G. Hofstra, D.W. Smith // 
Journal of Environmental Management. - 1984. Vol. 3. - № 19. - P. 261-272.

8. Эффективность очистки сточных вод предприятий угледобывающей промышленности / А.Е. Крутков, Ю.Л. Сколубович, Е.Л. Войтов, А.А. Цыба // Труды Новосибирского государственного архитектурно-строительного университета (Сибстрин). - 2017. - Т. 20. - № 1 (64). - С. 57-69.

9. Кичигин, В.И. Обработка и утилизация осадков природных и сточных вод : учебное пособие. / В.И. Кичигин, Е.Д Палагин. - Самара : Самарский государственный архитектурно-строительный университет, 2008. - 204 с.

\section{References}

1. Alekseev, M.I. Organizatsiya otvedeniya poverkhnostnogo (dozhdevogo i talogo) stoka s urbanizirovannykh territorii : ucheb.posobie [Organization of discharge of surface (rain and thawed) runoff from urbanized territories: a training manual]. Moscow, ASV Publ., 2000, 352 p. (In Russ., abstr. In Engl.)

2. Molokov M.V. Dozhdevaya kanalizatsiya ploshchadok promyshlennykh predpriyatii : proizvodstvenno-prakticheskoe izdanie. [Rain sewer sites of industrial enterprises: production and practical publication]. Moscow, Leningrad, Stroiizdat Publ., 1964, 184 p. (In Russ., abstr. In Engl.)

3. Volchek A.A., Bulskaya I.V. Livnevoi stok kak istochnik zagryazneniya poverkhnostnykh vod [Stormwater runoff as a source of surface water pollution]. Vestnik Brestskogo gosudarstvennogo tekhnicheskogo universiteta [Bulletin of the Brest State Technical University], 2012, Issue 2, pp. 41-43. (In Russ., abstr. In Engl.)

4. Govorova Zh.M., Govorov OB, Gandurina L.V., Butseva L.N. Ochistkalivnevogo poverkhnostnogo stoka na osvetlitel'no- sorbtsionnykh fil'trakh s primeneniem kationnykh flokulyantov [Purification of storm surface runoff on clarification-sorption filters using cationic flocculants]. Ochistka stochnykh vod: Sbornik trudov NIIVODGEO [Wastewater treatment: Collection of works of the Research Institute of VODGEO]. Moscow, NIIVODGEO Publ., 2004, Issue 7, pp. 52-61. (In Russ., abstr. In Engl.)

5. Ignatyev L. P., Potapova M. O. Sanitarnaya okhrana vodnykh ob"ektov: uchebnoe posobie [Sanitary protection of water bodies: a training manual]. Irkutsk, IGMU Publ., 2016, 97 p. (In Russ., abstr. In Engl.)

6. Fleck A.M., Lacki M.J., Sutherland J. Response by white birch (Betula papyrifera) to road salt applications at Cascade Lakes. Journal of Environmental Management, 1988, Vol. 12, no. 1, pp. 369-377.

7. Hofstra G., Smith D.W. The effects of road deicing salt on thelevels of ions in roadside soils in southern Ontario. Journal of Environmental Management, 1984, Vol. 3, no. 19, pp. 261-272.

8. Krutkov A.E., Skolubovich Yu.L., Voitov E.L., Tsyba A.A. Effektivnost' ochistki stochnykh vod predpriyatii ugledobyvayushchei promyshlennosti [The efficiency of wastewater treatment in coal mining enterprises]. Trudy Novosibirskogo gosudarstvennogo arkhitekturno-stroitel'nogo universiteta (Sibstrin) [Transactions of Novosibirsk State University of Architecture and Civil Engineering (Sibstrin)], 2017, Vol. 20, no. 1 (64), pp. 57-69. (In Russ., abstr. In Engl.)

9. Kichigin V.I., Palagin E.D. Obrabotka i utilizatsiya osadkov prirodnykh i stochnykh vod : uchebnoe posobie [Treatment and disposal of natural and waste water sludge] : uchebnoe posobie. Samara: Samarskii gosudarstvennyi arkhitekturno-stroitel'nyi universitet Publ., 2008, 204 p. (In Russ., abstr. In Engl.)

Сколубович Юрий Леонидович (Новосибирск). Доктор технических наук, профессор, член-корреспондент РААСН. Ректор ФГБУ В0 «Новосибирский государственный архитектурно-строительный университет» (Сибстрин) [630008, Новосибирск, ул. Ленинградская, д.113. НГАСУ (Сибстрин)]. Эл. почта: rector@sibstrin.ru.

Войтов Евгений Леонидович (Новосибирск). Доктор технических наук, доцент, советник РААСН. Профессор ФГБУ ВО «Новосибирский государственный архитектурно-строительный университет» (Сибстрин) [630008, Новосибирск, ул. Ленинградская, д. 113. НГАСУ (Сибстрин)]. Эл. почта: voitovel@ya.ru.

Цыба Анна Александровна (Новосибирск). Аспирант ФГБУ ВО «Новосибирский государственный архитектурно-строительный университет» (Сибстрин) [630008, Новосибирск, ул. Ленинградская, д.113. НГАСУ (Сибстрин)]. Эл. почта: anyuta.tsyba@ yandex.ru.

Балчугов Денис Валерьевич (Новосибирск). Аспирант ФГБОУ «НГАСУ (Сибстрин)» [630008, Новосибирск, ул. Ленинградская, д.113. НГАСУ (Сибстрин)]. Эл. почта: bal@sibstrin.ru.

Белоногов Дмитрий Евгеньевич (Новосибирск). Магистрант ФГБОУ «НГАСУ (Сибстрин)» [630008, Новосибирск, ул. Ленинградская, д.113. НГАСУ (Сибстрин)]. Эл. почта: bed-belon@yandex.ru.

Skolubovich Yuri Leonidovich (Novosibirsk). Doctor of Technical Sciences. Corresponding Member of RAASN; Rector of NGASU (Sibstrin) (630008, Novosibirsk, Leningradskaya st., 113. NGASU (Sibstrin).E-mail: rector@sibstrin.ru. 
Voitov Evgeny Leonidovich (Novosibirsk). Doctor of Technical Sciences. Advisor to RAASN; Professor NGASU (Sibstrin) [630008, Novosibirsk, Leningradskaya st., 113. NGASU (Sibstrin)]. E-mail: voitovel@ya.ru.

Tsyba Anna Alexandrovna (Novosibirsk). Post-graduate student of NGASU (Sibstrin) [630008, Novosibirsk, Leningradskaya st, 113. NGASU (Sibstrin)]. E-mail: anyuta.tsyba@yandex.ru.

Balchugov Denis Valerievich (Novosibirsk). Post-graduate student of NGASU (Sibstrin) [630008, Novosibirsk, Leningradskaya st., 113. NGASU (Sibstrin)]. E-mail: bal@sibstrin.ru.

Belonogov Dmitry Evgenievich (Novosibirsk). Master student of NGASU (Sibstrin) [630008, Novosibirsk, ul. Leningradskaya, d.113. NGASU (Sibstrin)]. E-mail: bed-belon@yandex.ru. 